\title{
Tendinitis calcificante de gastrocnemios
}

\section{Calcifying gastrocnemius tendinitis}

\author{
Miguel Antonio Mesa, Mauricio Restrepo • Medellín (Colombia)
}

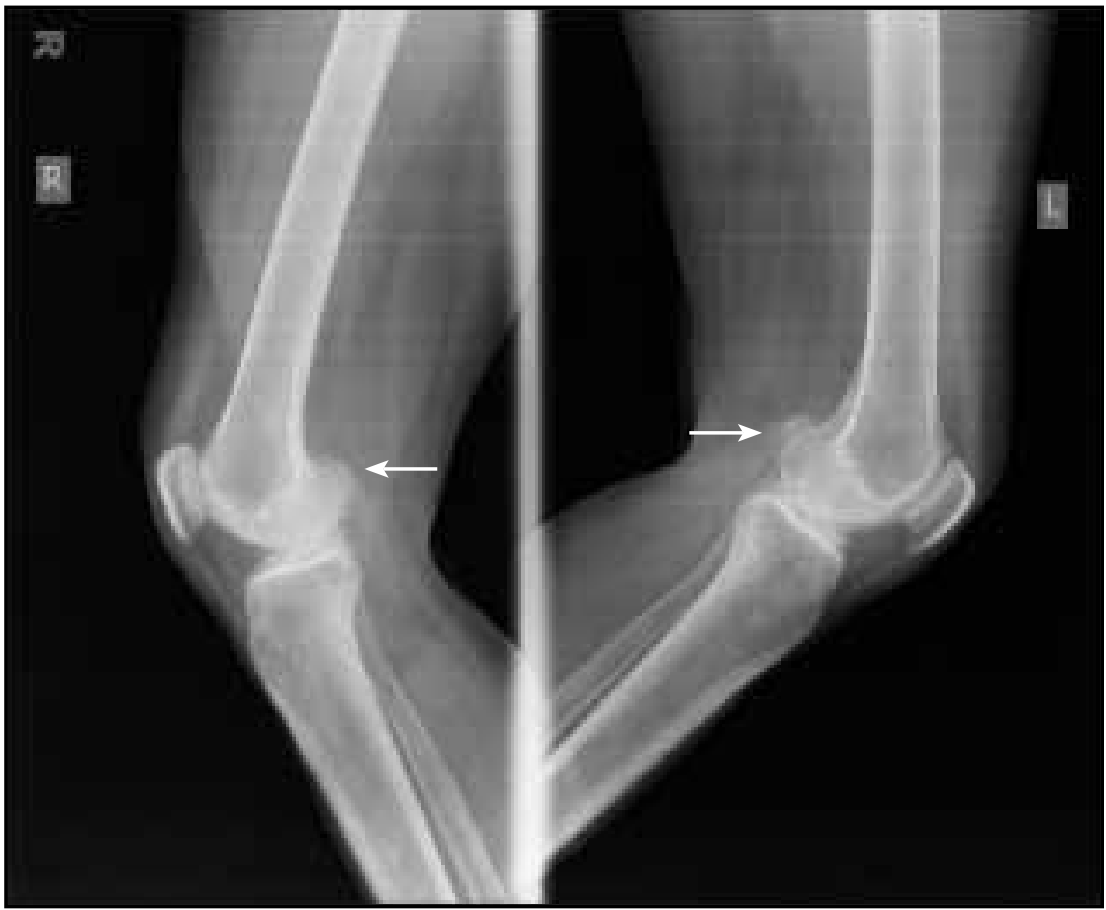

Figura 1. Condrocalcinosis, artrosis tricompartimental, osteopenia y calcificación de las inserciones de los tendones de los gastrocnemios.

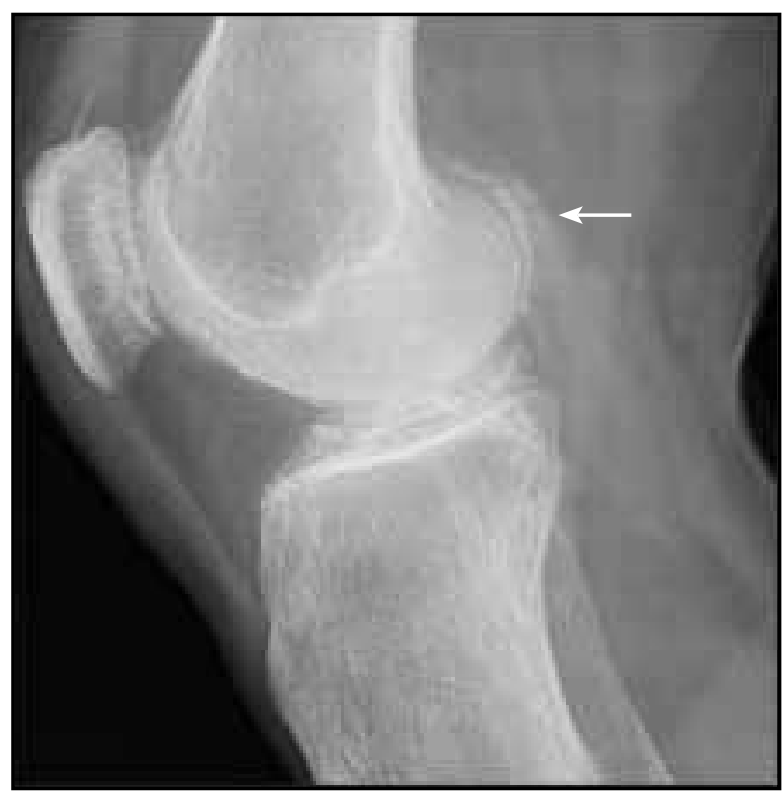

Figura 2. Ampliación. Rodilla derecha. Calcificación de las inserciones de los tendones de los gastrocnemios.
Mujer de 81 años quien consultó por poliartritis crónica semejando una artritis reumatoide. Documentamos una cifosis torácica por múltiples fracturas vertebrales, condrocalcinosis y calcificaciones tendinosas múltiples. Su artropatía se consideró secundaria a enfermedad por depósito de cristales de pirofosfato de calcio (CPPD). Hallamos hipercalcemia de $14.3 \mathrm{mg} / \mathrm{dL}$ y una parathormona de $525 \mathrm{pg} /$ ml. Observamos condrocalcinosis de cartílagos hialinos y fibrocartílagos, cambios artrósicos tricompartimentales, baja masa ósea y calcificación de las inserciones de los tendones de los gastrocnemios en forma bilateral. Fue derivada a endocrinología para el tratamiento de su hiperparatiroidismo primario.

En pacientes con CPPD se observan calcificaciones tendinosas en múltiples áreas especialmente en cuadriceps, Aquiles, triceps, cabeza larga del biceps, manguito rotador y gastrocnemios (1). La tendinitis calcificante de gastrocnemios es un hallazgo relativamente frecuente (sensibilidad $28.4-41 \%$ ) y patognomónico (especificidad 100\%) de CPPD (2, 3). Este hallazgo podría ser útil por la heterogeneidad de la presentación clínica de la artropatía por CPPD y porque en ocasiones puede ser difícil observar la condrocalcinosis en caso de que haya mucha destrucción del cartílago.

\section{Referencias}

1. Pereira ER, Brown RR, Resnick D. Prevalence and patterns of tendon calcification in patients with chondrocalcinosis of the knee: radiologic study of 156 patients. Clin Imaging 1998; 22(5): 371-5.

2. Yang BY, Sartoris DJ, Resnick D, Clopton P. Calcium pyrophosphate dihydrate crystal deposition disease: frequency of tendon calcification about the knee. J Rheumatol 1996; 23(5): 883-8.

3. Foldes K, Lenchik L, Jaovisidha S, Clopton P, Sartoris DJ, Resnick D. Association of gastrocnemius tendon calcification with chondrocalcinosis of the knee. Skeletal Radio 1996; 25(7): 621-4.

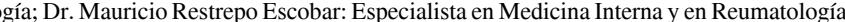
Profesor Auxiliar. Sección de Reumatología. Departamento de Medicina Interna. Facultad de Medicina. Universidad de Antioquia. Medellín (Colombia).

Correspondencia. Dr. Mauricio Restrepo. Medellín (Colombia).

E-mail: mauresco90@hotmail.com

Recibido: 16/VI/2012 Aceptado: 15/VIII/2012 